\title{
Bringing the Citizen back in: Motivational Aspects of Knowledge Sharing through Web 2.0 Technologies in Public Administration
}

\author{
Markus Wojtczak*, Michèle Morner**
}

*German Research Institute for Public Administration, Speyer, Germany; wojtczak@foev-speyer.de **German University of Administrative Sciences, Speyer, Germany; morner@uni-speyer.de

Abstract: In an effort to cope with an increasingly complex environment characterized by heterogeneous, diffuse or unknown public preferences, public administrations have begun using Web 2.0 internet technology to allow for direct citizen engagement in the generation of new knowledge. The success of such collaborative Web 2.0 websites depends largely on the citizens voluntarily sharing their knowledge. However, uncertainty about the outcome of the collaborative project might hinder citizens' motivation to share their knowledge. In this conceptual paper we explore antecedents for citizens' motivation to share their knowledge via collaborative Web 2.0 technologies. We provide a substantial review of literature on voluntary knowledge sharing in organizations which we transfer to the context of citizen-administration collaboration through Web 2.0 technologies. Based on that we formulate propositions on how to foster citizens' motivation for knowledge sharing and give advice for further research.

Keywords: Web 2.0, citizen-administration collaboration, knowledge sharing, motivation

\section{Introduction}

Ambitious targets and policy regulations on the one side and increasing citizen demands for public service provision on the other have contributed to a highly complex task setting (Agranoff \& McGuire, 2003; Ansell \& Gash, 2008; Bingham \& O'Leary, 2008). To ease the resulting burden, administrations are using Web 2.0 applications to accomplish their tasks through collaboration with citizens. Accordingly, they "engage people constructively across the boundaries of public agencies, levels of government, and/or the public, private and civic spheres in order to carry out a public purpose that could not otherwise be accomplished" (Emerson, Nabatchi, \& Balogh, 2011, p. 2).

The use of Web 2.0 thereby aims to achieve high degrees of participation and knowledge sharing among a large number of active citizens (Linders, 2012). Web 2.0 puts the user in an active role within a multi-directional communication network (O'Reilly, 2005); users not only consume but are also able to generate content on Web 2.0 websites, exemplified by the likes of Wikipedia, 
YouTube, Facebook, and Twitter, wherein they upload self-made videos or contribute to encyclopedia articles. Public administration has begun to use these social media technologies to engage with citizens and to collaborate with them (Meijer \& Thaens, 2013). Some contemporary examples employed by public administration include the "Peer To Patent" initiative of the United States Patent and Trademark Office and "FixMyStreet" in the UK, as well as participatory budgeting initiatives that municipalities across the globe increasingly operationalize in Web 2.0 environments (Sintomer, Herzberg, \& Rocke, 2008). We call these environments "collaborative" Web 2.0 environments, as they include instances of collaboration (Ansell \& Gash, 2008; McGuire, 2006). While collaboration may take many forms, in this paper we will focus on knowledge sharing, which is often a result of collaboration (Gagné, 2009; Cabrera \& Cabrera, 2005). Web 2.0 platforms have the potential to enable citizen collaboration with public administrations and thereby facilitate mutual contribution to a public purpose.

Literature on Web 2.0 until now has largely focused on the supply-side and neglected the usage-side, assuming citizens will use applications as soon as they are offered (Reddick, 2005). Authors of the supply-side literature derive frameworks and typologies to categorize egovernment services along different variables (Grant \& Chau, 2005; Linders, 2012; Moon, 2002). They show that e-government is used primarily in order to provide information to the populace, while opportunities for active citizen collaboration and participation seem to be underdeveloped (Sandoval-Almazan \& Gil-Garcia, 2012). Not surprisingly, actual public participation in Web 2.0 collaboration projects has been found to be underwhelming, thus drawing attention to the usageside of the problem.

The usage-side literature typically frames the challenges of e-government participation as one of acceptance of new technology by users (Carter \& Bélanger, 2005; Horst, Kuttschreuter, \& Gutteling, 2007). This strand is based on the Technology Acceptance Model introduced by Fred D. Davis (Davis, 1989), which finds that perceived usefulness and perceived ease of use explain the acceptance of new technologies. The Technology Acceptance Model, as a specification of the Theory of Reasoned Action (for a detailed description see section 2), is primarily interested in how attitudes translate into behaviour. Thus, it explains individual behaviour only partially, in that it ignores social factors and interpersonal relationships (Chang \& Chuang, 2011, p. 9). We want to add to this literature by eschewing the Technology Acceptance Model and instead opting to use the Theory of Planned Behaviour, which also incorporates normative pressures for behaviour as well as self-efficacy considerations. This broadens the theoretical scope and allows us to find further explanations for individual motivation to use Web 2.0 platforms in order to collaborate with public administration. Thus, we go beyond a technology-deterministic and positivistic view of e-government participation, one that deems availability and usefulness of applications as the key determinants of successful Web 2.0 projects (Heeks \& Bailur, 2007), by rediscovering the citizen and focusing on citizens' motivations for collaboration in Web 2.0 environments (Meijer, Curtin, \& Hillebrandt, 2012). Usually, citizens have different reasons to participate, like changing the outcome of a decision to their favour or to voice their personal values. In several cases, citizens' motivations may be similar. If, additionally, they share a common competence, a community of practice emerges (Wenger, 2000, p. 229). Our focus, however, lies on collaborations that appeal to a 
broad range of people that do not necessarily share a common characteristic or profession. Thereby we are seeking motivational antecedents that enable citizens' willingness to voluntarily share their knowledge using Web 2.0 collaboration platforms. Herein we define usage as an individual behaviour: Each citizen has to decide for themselves if they are willing to expend time and effort to use the Web 2.0 application. Thus, we need to find explanations for individual behaviour. By incorporating social interactivity mechanisms as well as motivational factors, and taking cues from socio-psychological and organization theories, we formulate propositions for the design of Web 2.0 applications that enable citizen-administration collaboration. We focus on collaborative Web 2.0 environments, as we believe that they are particularly capable of creating public value (Meijer \& Thaens, 2010). Citizens within these Web 2.0 projects share knowledge and engage with each other. Since Web 2.0 technology primarily allows for the sharing of knowledge, we will focus on voluntary knowledge sharing.

The remainder of this paper is structured as follows: In the second section we describe our theoretical approach by introducing the Theory of Planned Behaviour as well as surveying the literature on motivation for knowledge sharing stemming from organizational theory. Subsequently, we will focus on the different aspects that may explain motivations for knowledge sharing behaviour: social processes in general (section three) and the possibility to influence these social processes through recognition and appreciation (section four). For each aspect we derive propositions to foster participation in collaborative Web 2.0 projects and substantiate these with illustrative examples. We conclude with a summary and avenues for further research (section five).

\section{How to Explain Individual Knowledge Sharing Behaviour}

A prominent theory that explains individual behaviour is the Theory of Planned Behaviour (Ajzen, 2012), which was originally developed in the 1970s by Martin Fishbein and Icek Ajzen under the moniker "Theory of Reasoned Action" (Fishbein \& Ajzen, 1975). The Theory of Planned Behaviour stands in contrast to other contemporary explanations of human behaviour in that it neither explains human behaviour solely through institutions (religions, organizations, etc.) or personal attributes, nor does it assume a causal linearity that connects external stimuli with behaviour without any cognitive mediation on the part of the individual. As such explanations have been found to be empirically lacking (Ajzen, 1991, p. 180; Ajzen, 2012, p. 439), the Theory of Planned Behaviour reflects new experimental findings on the mental processes behind individual behaviour. Herein individual behaviour is explained through the intention to carry out said behaviour (Ajzen, 1985). This reflects motivational factors that determine the amount of effort an individual is willing to expend for a given behaviour (Ajzen, 1991, p. 181; Conner \& Armitage, 1998, p. 1430).

The Theory of Planned Behaviour identifies three beliefs that influence intention. Behavioural beliefs concern the subjective evaluation of the likely outcomes of pursuing a behaviour. Individuals hold subjective attitudes towards a behaviour based on their perception of the expected outcome. Normative beliefs stem from the perception of normative expectations of other people. Norms are rights to control that are held by others and can be based on consensus or be 
forced by authority. Expectations of others create social pressure and influence the individual's subjective norm towards a given behaviour. Already, these two beliefs can be used to explain a variety of situations. For example, an individual might have a positive attitude towards a behaviour, yet still not carry it out due to social pressure. The opposite may also hold true, as an individual engages in a behaviour that she or he does not have a positive attitude towards but which they feel compelled to do, due to social pressure. The final motivational antecedent introduced by Ajzen are control beliefs, which are a set of physical and mental circumstances that may serve to prohibit an individual from pursuing a behaviour, even if their attitude and subjective norm support it. Perceived behavioural control is the extent to which an individual believes herself or himself able to perform a behaviour and have control over the subsequent events, following the concept of Self-Efficacy (Bandura, 1982). Consequently, a person may have a high motivation towards a specific behaviour, yet still refrain from performing it because they believe themselves to be unable to affect the outcome despite their effort. The Theory of Planned Behaviour has been applied in different research areas, such as health, safety, social relations and politics, and has been found to be a reliable predictor of individual behaviour (Ajzen, 1985; Armitage \& Conner, 2001; Conner \& Armitage, 1998). Furthermore, it has been used as a foundation for the introduction of interventions designed to control and govern behaviour (Ajzen, 2012, p. 454). In conclusion, the Theory of Planned Behaviour guides our investigation of the motivational prerequisites for behaviour that stem from personal attitudes, social pressure and self-efficacy beliefs.

Why people feel motivated to share their knowledge and collaborate has long been a research focus in the organizational sciences (Foss, 2007; Grandori, 2001; Minbaeva \& Pedersen, 2010), as organizations are dependent on their employees' input and the sharing of individual knowledge if they want to innovate and succeed (Frost \& Morner, 2005). However, managers and supervisors cannot simply force their employees to share their individual knowledge (Frost \& Morner, 2010). Similarly, trying to incentivize employees through financial rewards alone does not function because of the nature of knowledge as a quasi-public good and the accompanying problems of evaluating each employee's contribution within a team's output (Frost, Osterloh, \& Weibel, 2010). There have been a number of recommendations to alleviate this problem and to find ways for employees to share knowledge and work together towards a mutual goal. These theories of knowledge sharing and collaboration are applicable to the context of Web 2.0 projects, since participants also have to collaborate and share knowledge voluntarily. In the case of supervisors, there is no direct correlate in the context of Web 2.0. However, in this social relationship with the participants, public officials can have a special position when they are organizing and maintaining the Web 2.0 platform. They provide the necessary infrastructure and are largely responsible for the design of the Web 2.0 projects. Therefore, public administration officials have a special relationship with the citizens and can use recognition and appreciation to incentivize knowledge sharing. Too strong a focus on government led top-down initiatives may on the other hand marginalize certain avenues for collaboration (Chadwick \& May, 2003). Thus, in this paper we will look for motivational cues for collaboration with a particular focus on bottom-up initiatives of citizen engagement. 


\section{Social Interactions as a Basis for Knowledge Sharing}

Many scholars have noted that a primary factor in what makes people motivated to share knowledge is to understand the social interactions within a group context (Chang \& Chuang, 2011; Kang \& Hau, 2014). Social interactions and interpersonal relationships play a primary role in the explanation of knowledge sharing intention, as stronger ties between individuals make knowledge sharing more likely (Chiu, Hsu, \& Wang, 2006). The effect of social ties on knowledge sharing has been theorized in the Social Capital Theory (Nahapiet \& Ghoshal, 1998), which states that social capital is "the sum of the actual and potential resources embedded within, available through, and derived from the network of relationships possessed by an individual or social unit" (Nahapiet \& Ghoshal, 1998, p. 243).

Nahapiet and Ghoshal have identified three dimensions of social capital: relational, structural and cognitive. Relational social capital refers to the qualitative nature of interpersonal relationships and the assets created through them (Nahapiet \& Ghoshal, 1998, p. 244). The assets that may be leveraged through social interactions are identification, commitment and trust (Chiu et al., 2006; Wasko \& Faraj, 2005). Structural social capital lies within the interaction ties inside a group and is often empirically operationalized by the length or duration of the relationship as well as the size of the group (Chiu et al., 2006; Kang \& Hau, 2014). The longer a group of people have shared a relationship with each other and the greater the number of strong ties between individuals, the more likely knowledge sharing between them will be (Wasko \& Faraj, 2005). Finally, cognitive social capital pertains to commonly shared interpretations within a group as manifested in shared visions (Tsai \& Ghoshal, 1998). Individuals that share a vision for a mutual goal will be more likely to collaborate, as they agree on the meaning and the value of knowledge sharing (Chiu et al., 2006). In accordance with the social capital framework, we will focus on the antecedents for knowledge sharing that lie within social interactions, namely: identification, commitment, trust, social tie duration, group size, and shared vision. This section will focus on social interactions between fellow participants in Web 2.0 applications, while section four emphasizes the relationship between participants and public officials.

Group identification has been linked to the individual need for social inclusion (Geen, 1991). In his Social Motivation Theory, Russel Geen describes a fundamental motive for individual behaviour as being a "[...] need to belong to, and be approved by, important social groups" (Geen, 1991, p. 395). Geen finds that people seek the approval of others. To that end, they will favour socially acceptable and rewarded behaviour and internalize group standards, goals and norms. However, people choose which groups they want to relate with and adapt selectively to that specific group's norms (Deci \& Ryan, 1985, p. 154). This not only leads individuals to be selfconscious and seeking of acceptance by others, but can at the same time be a motivating factor if people are engaging with others on a common task. In order to be accepted and gain approval by a group, individuals will be more likely to voluntarily share resources, such as their knowledge. On the basis of Social Motivation Theory, Quigley et al. (Quigley, Tesluk, Locke, \& Bartol, 2007) find that people's propensity for sharing knowledge is less based on their individual financial gain, but more on facilitating norms within a group. Paul and Anantharaman see team-based job design as 
an important factor for group identification (Paul \& Anantharaman, 2003, p. 1259). Having employees work together on a common task, especially when coupled with group-level rewards, will lead to more knowledge sharing. It facilitates teamwork as well as open discussion and creates a sense of group identity (Tajfel \& Turner, 1986). To sum up, group identification builds relational social capital and motivates individuals to share their knowledge and collaborate with others.

When individuals identify with their organization and their co-workers, they also show a high level of affective commitment that further fosters their propensity to share knowledge (Matzler, Renzl, Mooradian, Krogh, \& Mueller, 2011). Matzler et al. link this affective commitment, which refers to the emotional attachment and identification with an organization (Meyer \& Allen, 1991), to individual characteristics and suggest corporations select employees based on favourable social traits. Other studies have linked certain job characteristics to the fostering of group identification and affective commitment (Bhatnagar, 2014; Cabrera \& Cabrera, 2005). Camelo-Ordaz et al. (Camelo-Ordaz, García-Cruz, Sousa-Ginel, \& Valle-Cabrera, 2011) see affective commitment as an intermediary that explains the effect of group-level rewards and incentives on the propensity for knowledge sharing. They found that practices leading to stronger knowledge sharing are those that focus on creating a lasting relationship between employer and employees as well as among fellow employees. These practices include team-based rewards that incentivize knowledge sharing, team-building and recruitment strategies that take into consideration the fit between the applicant's and the organization's values (Camelo-Ordaz et al., 2011, p. 1446).

Group identification relies on trust, an element of relational social capital, which has been defined as "an actor's belief that a person or collectively will perform actions (including providing information) that will prove helpful or not detrimental to him or her, thus permitting the establishment of a relationship of cooperation" (Fine \& Holyfield, 1996). Therefore, trust is a quality of an interpersonal relationship and facilitates collaboration. Trust has also been found to relate to organizations and thereby to concerns of procedural justice (Mahajan \& Benson, 2013). Procedural justice is based on the perceived fairness of formal procedures of organizational decision-making (Lamertz, 2002). Employees will be more likely to accept managerial decisions, even adverse ones, if they perceive the decision-making procedure to be fair (Thompson \& Heron, 2005). Fairness perceptions of procedures and interpersonal relationships can be promoted on the basis of respect (Frey, Homberg, \& Osterloh, 2013, pp. 961-962). Another way to foster perceptions of fairness in organizational procedures is to allow employees to participate in the decisionmaking themselves (Pastor, Santana, \& Sierra, 2010). Employees that are able to participate in decision-making and perceive procedures to be fair show a higher propensity for knowledge sharing behaviour (Han, Chiang, \& Chang, 2010), while rules that are forced upon them externally may serve to weaken such behaviour (Frey, 1994). The rules that govern decision-making procedures, as well as how an employee can affect these rules, have to be transparent if they are to foster knowledge sharing motivation (Hsu \& Chang, 2014). Elinor Ostrom, through her studies on cooperation and public goods, has found a number of best practices for how procedural rules should be created and monitored in order to facilitate fairness perceptions and cooperation (Ostrom, 2000). Rules have to be monitored and a set of sanctions needs to be created that can be used to enforce said rules. Ostrom opts for the route of "mutual monitoring" between users, as this 
approach reinforces cooperation (Ostrom, 2000, p. 152). Sanctions should be gradual, meaning that the first rule infraction should be responded to with an informative gesture, while only further infractions lead to more severe consequences.

Transferring the aforementioned research, we can surmise that rules in Web 2.0 environments should be transparent regarding how individual contributions will influence the final outcome, if voluntary knowledge sharing is to be strengthened. The rules should be made public in a way that is easy to understand for the users and also easily accessible at any time during the project. Participation in the rule-making of Web 2.0 projects has its limits. Typically, Web 2.0 collaboration launches before citizen interaction is possible. Yet naturally, some rules have to be defined prior to launch. However, this process may be supported by offline participation and by asking affected citizens and potential users about their preferences regarding procedural rules. Also, earlier projects may provide guidelines for the design of new rules for new projects. Once the project has started, citizens should be encouraged to participate in rule modification. This may happen in a top-down manner, in which public officials offer rule changes for consideration, or bottom-up, with users able to propose rule changes themselves. Monitoring of rules and participants' contributions revolves around the role of the moderator. Internet forum moderators identify postings that violate rules and reprimand users for continued rule infractions. In keeping with the idea of mutual monitoring, moderators could be selected from the users. Alternatively, moderation could be completely delegated to the participants themselves, by allowing each user to flag specific postings that they deem to be in violation of the rules. This would still necessitate an impartial moderator, who verifies whether flagged postings indeed violate the rules, in order to prevent users from flagging opinions simply because they disagree with them. Sanctions for rule violations should start with a message to the relevant user as well as a general notice about how her or his specific posting violated the rules. Only further rule infractions would warrant stronger reactions, up to banning a given user from further participation.

Proposition 1: If rules are transparent and perceived as fair, they foster knowledge sharing in Web 2.0 environments.

Given fair procedures, individuals not only identify with other group members, but may also identify with the task itself (Cabrera \& Cabrera, 2005; Foss, Minbaeva, Pedersen, \& Reinholt, 2009). Employees perceive the meaningfulness of a task based on their own role within that task and derive motivation therefrom. If an employee is able to work at a task from its beginning to its end, she or he will perceive it as a whole and is more likely to identify with it and be more motivated to commit effort to complete the task. Thus, the probability of knowledge sharing is dependent on the project's duration. Collaborative Web 2.0 projects' durations should ideally be prolonged to the greatest extent possible and not be confined to a singular ad-hoc meeting. Identification and normbuilding need time to develop and require continuous interaction between individuals of the same group. Another factor of the structural dimension of social capital is the group's size. Social Motivation Theory identifies a process of "Social Loafing" (Geen, 1991, p. 384): If a group grows larger, the individual will perceive their individual effect on the outcome of the group project lessens and will adjust their expended effort accordingly. Bearing in mind the size of a group and its effect on motivation, one might suggest organizing in smaller groups. Smaller teams working 
on a mutual task may find it easier to create identification, as they have stronger interaction ties (Mäkelä \& Brewster, 2009). For example, within the "LiquidFeedback"-framework that has been used by Germany's Pirate Party, as well as the Five Star Movement in Italy, participants are able to specialize in a single issue area. This means that people who are specifically interested in one policy area are able to work together more closely. In this way participants form stronger interaction ties with each other and build knowledge sharing norms. Furthermore, Web 2.0 collaboration should continue as one part of the public policy making cycle for its whole duration, from a proposal's preliminary inception through the planning stage and up to the final implementation.

Proposition 2: Web 2.0 groups with strong interaction ties develop knowledge sharing norms.

Proposition 3: If people work together for an extended period of time through Web 2.0 platforms, they develop knowledge sharing norms.

Small team size will only foster interaction if opportunities for collaboration are provided (McGeer, 2004). The implication of this for collaborative Web 2.0 platforms is that they should enable participants to engage with each other and work towards a common goal. Participants have to be able to see contributions made by others and comment on them. Web 2.0 projects should have a specified purpose so that participants can feel like they are contributing to a mutual goal. Tasks need to be designed in a way that interdependencies are created, furthering interaction between participants and opportunities for collaboration. A mutual goal does not presuppose identical preferences or consensus, but will make it more likely that participants will share their knowledge and collaborate.

Proposition 4: Mutual goals that create interdependencies foster voluntary knowledge sharing on Web 2.0 platforms.

Proposition 5: Opportunities for collaboration toward a mutual goal foster voluntary knowledge sharing on Web 2.0 platforms.

In conclusion, motivation for knowledge sharing can be increased by more intensive group interactions. Working in a group on a mutual task satisfies the socio-psychological need for belonging and serves to strengthen the identification of the individual with the group as well as with the group's task.

\section{The Role of the Recognition and Appreciation for Incentivizing Knowledge Sharing}

While the previous section focused on social interactions between participants in Web 2.0 collaborations, in this section we will look at interactions between participants and public officials. We have argued that the relationship between citizens participating in Web 2.0 collaborations and public officials demands special attention as public officials can incentivize knowledge sharing, in a similar way as supervisors incentivize their employees. Employee-supervisor relations are 
categorized by different leadership styles, wherein Transformational Leadership has been found to build social capital as well as foster collaboration and knowledge sharing (Bono \& Anderson, 2005; Maak, 2007). Transformational leadership is typically defined in contrast to transactional leadership, with its focus on the financial exchange between employee and employer (Bass, 1990). Transformational leadership, on the other hand, focuses on social exchange (Blau, 1964) and seeks to support employees, valuing their contribution ("Individual Consideration"), encouraging new ideas ("Intellectual Stimulation"), articulating a shared vision as a meaningful purpose ("Inspirational Motivation") and leading through example thereby embodying the articulated vision ("Idealized Influence") (Bass \& Riggio, 2006). Thus, employees are motivated to contribute beyond their own self-interest and focus on the organization's vision.

As the concept of Individual Consideration posits, individual knowledge sharing contributions should be valued and may be part of employee performance evaluations (Carmeli, Gelbard, \& Reiter-Palmon, 2013, pp.114-116). One form of motivating is through social rewards, such as recognition and appreciation by supervisors and co-workers (Bhatnagar, 2014; Biswas, Varma, \& Ramaswami, 2013). When employees receive feedback about their performance that is perceived as encouraging and informative, knowledge sharing motivation is strengthened (Foss et al., 2009). If employees that excel at sharing knowledge are recognized and encouraged, it serves as a recurring reminder for all employees that knowledge sharing is seen as an important value within the organization (Quigley et al., 2007, p. 83). Respect and recognition from the side of the supervisor helps in creating a relationship of trust, which in turn fosters knowledge sharing motivation (Kuvaas, Buch, \& Dysvik, 2012). The employee reacts with long-term commitment towards that relationship and will perceive normative pressure to reciprocate by sharing knowledge (Cabrera, Collins, \& Salgado, 2006).

In a Web 2.0 context, the recognition and appreciation that seeks to inspire citizens can be realized in a variety of ways. Individual contributions to ongoing discussions must not go unrecognized. It increases the feeling of being appreciated if the participants know their input is not being overlooked, but rather that they are able to impact the outcome of the collaboration project. A commentary function that allows for interaction of public officials with the participants will strengthen participants' propensity for collaboration by increasing their perception of appreciation by others. Public officials should engage with participants and give supportive feedback. In the case of incentives, participants' postings and commentaries could qualify for awards and similar forms of individual recognition, when they are detailed, informative or otherwise of high quality. Recognition of individual contributions will make them stand out as examples of knowledge sharing, thereby showing other participants the value of collaboration. Additionally, Web 2.0 collaboration projects could introduce a metric that quantifies the number of postings by an individual participant as well as their quality. A model for this could be social news aggregator sites like Slashdot or Reddit, where users submit articles they found on other news outlets' websites. Other users then rate these submissions based on their informative value and relevance, while users that regularly submit highly ranked articles receive a higher overall score. Unlike the personal feedback of public officials and other participants, this could be an automated method for quantitative recognition. The quality of a posting could be operationalized through the 
number of follow-up commentaries and questions it generates or, depending on the nature of the collaboration project, how many votes the proposal accrues. Web 2.0 applications also often allow for "likes" (e.g., Facebook) by other users that do not convey the weight of a cast vote but do give a scale of general approval. This metric can incentivize participants to expend more effort in their contributions and to make more postings, resulting in a higher propensity for knowledge sharing and collaboration.

Proposition 6: Knowledge sharing in Web 2.0 platforms can be incentivized through recognition and appreciation in the form of individual commentaries or metrics.

In line with transformational leadership's Inspirational Motivation and Idealized Influence, a shared vision facilitates knowledge sharing by creating a common ground that makes it easier and more likely for employees to collaborate (Chiu et al., 2006; Hsu \& Chang, 2014, p. 124). Shared Vision is a set of "collective goals and aspirations of the members of an organization" (Tsai \& Ghoshal, 1998). Visions transcend specific tasks and are more generalized notions of favourable conditions and situations that may be realized in the intermediate future. Single departments and business units within a firm can have independent, even conflicting, goals yet a shared vision across the corporation and this can ensure a greater propensity for collaboration across such groups (Wong, Tjosvold, \& Liu, 2009). Carmeli et al. (Carmeli et al., 2013) point out that leaders should be selected based on their ability to be a role-model for knowledge sharing and already appointed leaders should be trained in the transformational leadership style. Transformational leaders communicate a common knowledge sharing vision and lead by example in order to encourage their employees to appreciate knowledge sharing behaviour. If leaders are able to foster an environment of open discussion with their employees, tolerating failure, not focusing on blaming employees for problems and encouraging new ideas, then they can inspire further knowledge sharing (Carmeli et al., 2013, pp. 114-116; Nahapiet \& Ghoshal, 1998, p. 255).

Public officials engaged in collaborative Web 2.0 projects should lead by example, communicate openly by sharing knowledge and disseminate a knowledge sharing vision, thus compelling participants to likewise share knowledge and collaborate. Participants will perceive that open communication and knowledge sharing are favourable behaviours. Public employees should disclose all documents pertaining to the topic of the collaboration project. They should make clear how all tasks and discussions are relevant for achieving their mutual goal. In the public relations efforts surrounding the collaboration project, they should frame the project as being part of a greater knowledge sharing vision that seeks to include all citizens. Furthermore, public officials can actively engage in discussions with the participants, not by trying to convince the participants of their own preferred outcome, but by adding further knowledge if needed, providing additional perspectives and encouraging further comments. Public personnel will have to be selected and trained on the basis of their ability to be transformational leaders and encourage a shared vision.

Proposition 7: Articulating and embodying a knowledge sharing vision will foster collaboration in Web 2.0 environments.

In conclusion, appreciation and acknowledgement as well as a shared vision are motivating factors in Web 2.0 collaborations. These factors can be attained through regular and constructive 
feedback that values knowledge sharing behaviour and through public officials seeking a social exchange with citizens that encourages collaboration through vision articulation and exemplary knowledge sharing.

\section{Conclusion}

This paper has derived propositions for the design of collaborative Web 2.0 platforms to foster active engagement by citizens in knowledge sharing. Social group interactions have been shown to be an important facilitator of knowledge sharing and collaboration. Social pressure to share knowledge is more likely to exist if a group of people can interact with each other over a longer period of time in adequately sized groups. The rules that govern interaction among participants need to be transparent and fair as well as allow for user participation in the modification and monitoring of said rules. Public officials can take a lead in these projects by communicating a shared vision and showing appreciation for participants' knowledge sharing. We have given examples of how these design propositions can be applied in the Web 2.0 context. The nature of a specific Web 2.0 collaboration project might, however, hinder the realization of some of these propositions. While transparency about the rules and the goal of the project should be possible to achieve easily, our proposition regarding the prolonged duration of collaborative relationships as a facilitator of knowledge sharing will possibly be harder to achieve, when decisions need to be reached quickly or the government body is already in a late stage of the decision-making process. However, we would argue that exactly for these reasons, it behoves public administration to think early about the use of collaboration. Furthermore, our propositions regarding the role of public officials could mean additional work for the public employees involved and thus be met with scepticism by administrations faced with budget constraints. Nonetheless, we have argued that allowing the users to moderate themselves and having a technical solution for the automatic acknowledgment of user contributions can at the same time increase motivation towards knowledge sharing and ease the workload of individual public employees. In a next step, the propositions formulated in this paper will be operationalized and tested through a quantitative survey study. This would validate our propositions and contribute to the development of a comprehensive framework for the design of Web 2.0 applications that effectively fosters citizenadministration collaboration.

\section{References}

Agranoff, R., \& McGuire, M. (2003). Collaborative public management: new strategies for local governments. American governance and public policy. Washington, D.C.: Georgetown University Press.

Ajzen, I. (1985). From Intentions to Actions: A Theory of Planned Behaviour. In J. Kuhl (Ed.), Springer series in social psychology. Action control. From cognition to behaviour (pp. 11-39). Berlin: Springer.

Ajzen, I. (1991). The theory of planned behaviour. Organizational Behaviour and Human Decision Processes, 50(2), 179-211. 
Ajzen, I. (2012). The Theory of Planned Behaviour. In Lange, Paul A. M. Van (Ed.), Handbook of Theories of Social Psychology. Volume 1 (pp. 438-460). Los Angeles: SAGE.

Ansell, C., \& Gash, A. (2008). Collaborative governance in theory and practice. Journal of Public Administration Research and Theory, 18(4), 543-571.

Armitage, C. J., \& Conner, M. (2001). Efficacy of the Theory of Planned Behaviour: A meta-analytic review. British Journal of Social Psychology, 40(4), 471-499.

Bandura, A. (1982). Self-Efficacy Mechanism in Human Agency. American Psychologist, 37(2), 122-147.

Bass, B. M. (1990). From transactional to transformational leadership: Learning to share the vision. Organizational Dynamics, 18(3), 19-31.

Bass, B. M., \& Riggio, R. E. (2006). Transformational leadership (2. ed). Mahwah, NJ: L. Erlbaum Associates.

Bhatnagar, J. (2014). Mediator analysis in the management of innovation in Indian knowledge workers: the role of perceived supervisor support, psychological contract, reward and recognition and turnover intention. The International Journal of Human Resource Management, 25(10), 1395-1416.

Bingham, L. B., \& O'Leary, R. (Eds.). (2008). Big ideas in collaborative public management. Armonk, NY: M.E. Sharpe.

Biswas, S., Varma, A., \& Ramaswami, A. (2013). Linking distributive and procedural justice to employee engagement through social exchange: a field study in India. The International Journal of Human Resource Management, 24(8), 1570-1587.

Blau, P. M. (1964). Exchange and power in social life. New York: J. Wiley.

Bono, J. E., \& Anderson, M. H. (2005). The advice and influence networks of transformational leaders. Journal of Applied Psychology, 90(6), 1306-1314.

Cabrera, A., Collins, W. C., \& Salgado, J. F. (2006). Determinants of individual engagement in knowledge sharing. The International Journal of Human Resource Management, 17(2), 245-264.

Cabrera, E. F., \& Cabrera, A. (2005). Fostering knowledge sharing through people management practices. The International Journal of Human Resource Management, 16(5), 720-735.

Camelo-Ordaz, C., García-Cruz, J., Sousa-Ginel, E., \& Valle-Cabrera, R. (2011). The influence of human resource management on knowledge sharing and innovation in Spain: the mediating role of affective commitment. The International Journal of Human Resource Management, 22(7), 1442-1463.

Carmeli, A., Gelbard, R., \& Reiter-Palmon, R. (2013). Leadership, Creative Problem-Solving Capacity, and Creative Performance: The Importance of Knowledge Sharing. Human Resource Management, 52(1), 95-121.

Carter, L., \& Bélanger, F. (2005). The utilization of e-government services: citizen trust, innovation and acceptance factors. Information Systems Journal, 15(1), 5-25.

Chadwick, A., \& May, C. (2003). Interaction between States and Citizens in the Age of the Internet: "eGovernment" in the United States, Britain, and the European Union. Governance, 16(2), 271-300. 
Chang, H. H., \& Chuang, S.-S. (2011). Social capital and individual motivations on knowledge sharing: Participant involvement as a moderator. Information \& Management, 48(1), 9-18.

Chiu, C.-M., Hsu, M.-H., \& Wang, E. T. (2006). Understanding knowledge sharing in virtual communities: An integration of social capital and social cognitive theories. Decision Support Systems, 42(3), 18721888.

Conner, M., \& Armitage, C. J. (1998). Extending the Theory of Planned Behaviour: A Review and Avenues for Further Research. Journal of Applied Social Psychology, 28(15), 1429-1464.

Davis, F. D. (1989). Perceived Usefulness, Perceived Ease of Use, and User Acceptance of Information Technology. MIS Quarterly, 13(3), 319-340.

Deci, E. L., \& Ryan, R. M. (1985). Intrinsic motivation and self-determination in human behaviour. Perspectives in social psychology. New York, NY: Plenum Press.

Emerson, K., Nabatchi, T., \& Balogh, S. (2011). An Integrative Framework for Collaborative Governance. Journal of Public Administration Research and Theory, 22(1), 1-29.

Fine, G. A., \& Holyfield, L. (1996). Secrecy, Trust, and Dangerous Leisure: Generating Group Cohesion in Voluntary Organizations. Social Psychology Quarterly, 59(1), 22-38.

Fishbein, M., \& Ajzen, I. (1975). Belief, attitude, intention and behaviour: An introduction to theory and research. Addison-Wesley series in social psychology. Reading, Mass.: Addison-Wesley.

Foss, N. J. (2007). The Emerging Knowledge Governance Approach: Challenges and Characteristics. Organization, 14(1), 29-52.

Foss, N. J., Minbaeva, D. B., Pedersen, T., \& Reinholt, M. (2009). Encouraging knowledge sharing among employees: How job design matters. Human Resource Management, 48(6), 871-893.

Frey, B. S., Homberg, F., \& Osterloh, M. (2013). Organizational Control Systems and Pay-for-Performance in the Public Service. Organization Studies, 34(7), 949-972.

Frey, B. S. (1994). How Intrinsic Motivation is Crowded out and in. Rationality and Society, 6(3), 334-352.

Frost, J., \& Morner, M. (2005). Corporate commons: sustaining competitiveness through public goods in multidivisional firms. International Journal of Learning and Change, 1(1), 28-45.

Frost, J., \& Morner, M. (2010). Overcoming knowledge dilemmas: governing the creation, sharing and use of knowledge resources. International Journal of Strategic Change Management, 2(2), 172-199.

Frost, J., Osterloh, M., \& Weibel, A. (2010). Governing Knowledge Work. Organizational Dynamics, 39(2), 126-136.

Gagné, M. (2009). A model of knowledge-sharing motivation. Human Resource Management, 48(4), 571-589.

Geen, R. G. (1991). Social Motivation. Annual review of psychology, 42(1), 377-399.

Grandori, A. (2001). Neither Hierarchy nor Identity: Knowledge-Governance Mechanisms and the Theory of the Firm. Journal of Management \& Governance, 5(3-4), 381-399. 
Grant, G., \& Chau, D. (2005). Developing a Generic Framework for E-Government. Journal of Global Information Management, 13(1), 1-30.

Han, T.-S., Chiang, H.-H., \& Chang, A. (2010). Employee participation in decision making, psychological ownership and knowledge sharing: mediating role of organizational commitment in Taiwanese hightech organizations. The International Journal of Human Resource Management, 21(12), 2218-2233.

Heeks, R., \& Bailur, S. (2007). Analyzing e-government research: Perspectives, philosophies, theories, methods, and practice. Government Information Quarterly, 24(2), 243-265.

Horst, M., Kuttschreuter, M., \& Gutteling, J. M. (2007). Perceived usefulness, personal experiences, risk perception and trust as determinants of adoption of e-government services in The Netherlands. Computers in Human Behaviour, 23(4), 1838-1852.

Hsu, M.-H., \& Chang, C.-M. (2014). Examining interpersonal trust as a facilitator and uncertainty as an inhibitor of intra-organisational knowledge sharing. Information Systems Journal, 24(2), 119-142.

Kang, M., \& Hau, Y. S. (2014). Multi-level analysis of knowledge transfer: A knowledge recipient's perspective. Journal of Knowledge Management, 18(4).

Kuvaas, B., Buch, R., \& Dysvik, A. (2012). Perceived training intensity and knowledge sharing: Sharing for intrinsic and prosocial reasons. Human Resource Management, 51(2), 167-187.

Lamertz, K. (2002). The social construction of fairness: social influence and sense making in organizations. Journal of Organizational Behaviour, 23(1), 19-37.

Linders, D. (2012). From e-government to we-government: Defining a typology for citizen coproduction in the age of social media. Government Information Quarterly, 29(4), 446-454.

Maak, T. (2007). Responsible Leadership, Stakeholder Engagement, and the Emergence of Social Capital. Journal of Business Ethics, 74(4), 329-343.

Mahajan, A., \& Benson, P. (2013). Organisational justice climate, social capital and firm performance. Journal of Management Development, 32(7), 721-736.

Mäkelä, K., \& Brewster, C. (2009). Interunit interaction contexts, interpersonal social capital, and the differing levels of knowledge sharing. Human Resource Management, 48(4), 591-613.

Matzler, K., Renzl, B., Mooradian, T., Krogh, G. von, \& Mueller, J. (2011). Personality traits, affective commitment, documentation of knowledge, and knowledge sharing. The International Journal of Human Resource Management, 22(2), 296-310.

McGeer, V. (2004). Developing Trust on the Internet. Analyse \& Kritik. Zeitschrift für Sozialtheorie, 26, 91107.

McGuire, M. (2006). Collaborative public management: Assessing what we know and how we know it. Public Administration Review, 66(S), 33-43.

Meijer, A. J., Curtin, D., \& Hillebrandt, M. (2012). Open government: connecting vision and voice. International Review of Administrative Sciences, 78(1), 10-29. 
Meijer, A., \& Thaens, M. (2010). Alignment 2.0: Strategic use of new internet technologies in government. Government Information Quarterly, 27(2), 113-121.

Meijer, A., \& Thaens, M. (2013). Social media strategies: Understanding the differences between North American police departments. Government Information Quarterly, 30(4), 343-350.

Meyer, J. P., \& Allen, N. J. (1991). A three-component conceptualization of organizational commitment. Human Resource Management Review, 1(1), 61-89.

Minbaeva, D., \& Pedersen, T. (2010). Governing individual knowledge-sharing behaviour. International Journal of Strategic Change Management, 2(2/3), 200.

Moon, M. J. (2002). The Evolution of E-Government among Municipalities: Rhetoric or Reality? Public Administration Review, 62(4), 424-433.

Nahapiet, J., \& Ghoshal, S. (1998). Social Capital, Intellectual Capital, and the Organizational Advantage. Academy of Management Review, 23(2), 242-266.

O'Reilly, T. (2005). What Is Web 2.0: Design Patterns and Business Models for the Next Generation of Software. Retrieved from http:// oreilly.com/web2/archive/what-is-web-20.html

Ostrom, E. (2000). Collective Action and the Evolution of Social Norms. The Journal of Economic Perspectives, 14(3), 137-158.

Pastor, I. P., Santana, P. P., \& Sierra, C. M. (2010). Managing knowledge through human resource practices: empirical examination on the Spanish automotive industry. The International Journal of Human Resource Management, 21(13), 2452-2467.

Paul, A. K., \& Anantharaman, R. N. (2003). Impact of people management practices on organizational performance: analysis of a causal model. International Journal of Human Resource Management, 14(7), 1246-1266.

Quigley, N. R., Tesluk, P. E., Locke, E. A., \& Bartol, K. M. (2007). A Multilevel Investigation of the Motivational Mechanisms Underlying Knowledge Sharing and Performance. Organization Science, 18(1), 71-88.

Reddick, C. G. (2005). Citizen interaction with e-government: From the streets to servers? Government Information Quarterly, 22(1), 38-57.

Sandoval-Almazan, R., \& Gil-Garcia, J. R. (2012). Are government internet portals evolving towards more interaction, participation, and collaboration? Revisiting the rhetoric of e-government among municipalities. Government Information Quarterly, 29, S72.

Sintomer, Y., Herzberg, C., \& Rocke, A. (2008). Participatory budgeting in Europe: Potentials and challenges. International Journal of Urban and Regional Research, 32(1), 164-178.

Tajfel, H., \& Turner, J. C. (1986). The Social Identity Theory of Intergroup Behaviour. In S. Worchel \& W. G. Austin (Eds.), The @Nelson-Hall series in psychology. Psychology of intergroup relations (2nd ed., pp. 7-24). Chicago: Nelson-Hall. 
Thompson, M., \& Heron, P. (2005). The difference a manager can make: organizational justice and knowledge worker commitment. The International Journal of Human Resource Management, 16(3), 383-404.

Tsai, W. P., \& Ghoshal, S. (1998). Social capital and value creation: The role of intrafirm networks. Academy of Management Journal, 41(4), 464-476.

Wasko, M. M., \& Faraj, S. (2005). Why Should I Share? Examining Social Capital and Knowledge Contribution in Electronic Networks of Practice. MIS Quarterly, 29(1), 35-57.

Wenger, E. (2000). Communities of Practice and Social Learning Systems. Organization, 7(2), 225-246.

Wong, A., Tjosvold, D., \& Liu, C. (2009). Cross-Functional Team Organizational Citizenship Behaviour in China: Shared Vision and Goal Interdependence Among Departments1. Journal of Applied Social Psychology, 39(12), 2879-2909.

\section{About the Authors}

Markus Wojtczak

Markus Wojtczak is a research fellow at the German Research Institute for Public Administration in Speyer. He has a Master's degree in sociology and is currently working on his PhD. His research interests include organisational theory, knowledge governance and crowdsourcing.

\section{Michèle Morner}

Michèle Morner is the Chair of Public Management and Leadership at the German University of Administrative Sciences in Speyer. She gives lectures in the field of strategic management, organisational theory and leadership. Her research interests include behavioural governance of organisational processes. She is Managing Director of the Institute for Corporate Governance at the University of Witten/Herdecke. 